\title{
The Located Making Framework for supporting craft maker enterprises in China
}

\author{
Stuart Walkera, Martyn Evans ${ }^{b}$, Wanlin Zhanga* \\ a ImaginationLancaster Design Research Centre, Lancaster University, Lancaster LA1 4YW, UK \\ ${ }^{b}$ Manchester School of Art, Manchester Metropolitan University, Manchester, UK \\ *Corresponding author e-mail: w.zhang12@lancaster.ac.uk
}

\begin{abstract}
:
This paper presents the Located Making Framework to support small maker enterprises in China who employ craft making practices by helping ensure a) their decision-making aligns with the fundamental values driving the enterprise; $b$ ) they are fully utilising local support opportunities; c) they align with principles of sustainability; and d) design opportunities are identified. Using constructivist methods (observations, interviews etc.), primary data was collected in the Yellow River Valley region, coded and analysed, and values and context-relationships interpreted from results. This framework, adapted to the Chinese context, is the latest iteration of a model initially developed from our research in the USA and the UK. The Chinese findings are shown in specially developed graphic formats that are readily understandable and lend themselves to ease of use. Future work to increase the reach of the research includes development of an online interactive framework to automatically generate individual and cumulative results.
\end{abstract}

Keywords: small maker enterprises; craft; sustainability; values

\section{Introduction}

Today, there is a renaissance of interest in and re-appreciation of craft and traditional making practices all around the world (Luckman and Andrew, 2020, p.4). In some cases, the application of design research expertise is offering ways of unlocking the potential of traditional material cultures by helping ensure they are appreciated while also being relevant and meaningful to contemporary needs (Tung, 2012; Temeltaş, 2017). However, some unrealistic or superficial design interventions that lack cultural appropriateness and context-sensitive, sustainable considerations have been criticised (e.g. Bissett-Johnson and Moorhead, 2019; Murray, 2012). Therefore, there needs to be a better understanding of how design expertise can contribute to the development of suitable support for the creative economy that is respectful of cultural legacy of place, and in accord with contemporary understandings of sustainability, inclusivity and resilience.

This research has been supported by UK Arts and Humanities Research Council (AHRC) Newton funding extending previously funded projects, namely: Design Routes, which examined culturally 
significant products, practices and designs through, amongst other things, key informant interviews with craft makers in New Mexico, USA; Design Ecologies, which included cultural exchange with researchers at the Chinese Academy of Social Sciences in Beijing and interviews with craft makers in China; and Living Design, which focussed on the values and ties to place of small maker enterprises in Cumbria in northwest England, UK. In the course of this research, we have progressively developed ways of understanding and visualizing the values, motivations and priorities of $\mathrm{craft}$ makers and the relationships they have to the place and culture in which they pursue their work, which provides the foundation of our most recent project, Located Making, conducted in conjunction with colleagues at the Beijing Institute of Fashion Technology and Ningxia University, China (see the interrelation of these research projects in Figure 1).

This paper presents the results of key informant interviews with skilled craft makers in the Yellow River Valley region of central China. We explain the methods and the analytical framework we used along with the findings, and we include the visualisation tools we have developed to effectively convey the results in relation to 1 ) the spectrum of human values, as articulated by Schwartz (2012); 2) the relationship of the crafts to place; and 3) to Walker's Quadruple Bottom Line of Design for Sustainability (2011, p.187-190; 2014, p.92-93). We also present 4) a visualisation tool for craftspeople to identify opportunities where design can contribute to their enterprise in ways that are appropriate to the product types they produce and are in line with their values.

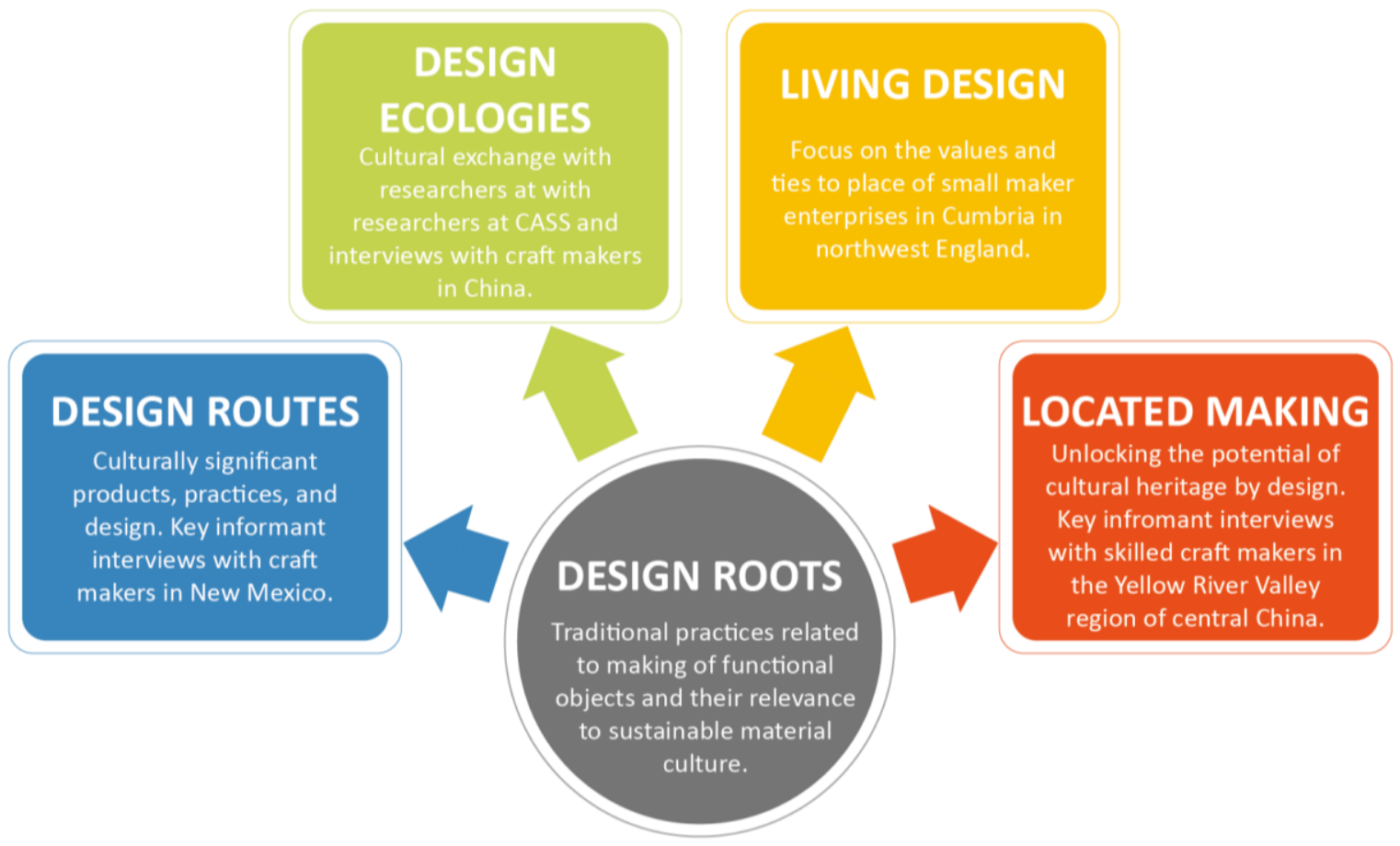

Figure 1 Inter-related research projects.

\section{Methods and analytical framework}

\subsection{Research methods}

In response to the UNESCO (the United Nations Educational, Scientific and Cultural Organisation) Convention for the Safeguarding of Intangible Culture Heritage (ICH) (2003), the Chinese government has, since 2004, been implementing a mechanism characterised as a combination of central initiative and local participation to create its own ICH and ICH Inheritors lists at multiple 
levels (Kuah and Liu, 2016). To better understand heritage making practices within the Chinese context, central China, including three provinces (Henan, Hubei and Hunan), was selected as a case study for the development of this research. At its heart lies the Yellow River Valley, an important site for Chinese civilisation with the origins of the Erlitou culture dating to the Bronze Age, as well as the Central Plain culture (Wang et al., 2020; China Daily, 2017). Fifty-seven local traditional crafts have been identified as having national significance under UNESCO's ICH Convention (ICH China, n.d.). This region is also supported by the "Rise of Central China" Plan, which is a policy adopted by the central government to accelerate development of its central area (CGSS, 2012). As a consequence, this region has experienced rapid urbanisation, modernisation and economic growth in recent years (Wang, 2019). In this background, both challenges and opportunities co-exist in relation to the continuation and development of local crafts.

A constructivist methodology (Crotty, 1998, p.42) was employed in the research that draws upon local knowledge and local values of makers and enterprise owners. Semi-structured interviews were carried out with over twenty micro maker-enterprises/studios and observational studies made during visits in order to understand their working environment and making process. Craft enterprises selected from this region were purposive, focusing on different craft fields within China's ICH programme, mainly in seven categories (textiles, musical instruments, paper crafts, metalwork, and carved artefacts, bamboo/straw crafts, and lacquer crafts) (See Figure 2). Data was coded and thematically analysed within the analytical framework (see framework details in section 2.2), and values (low, medium, high) for the framework plots interpreted from results.

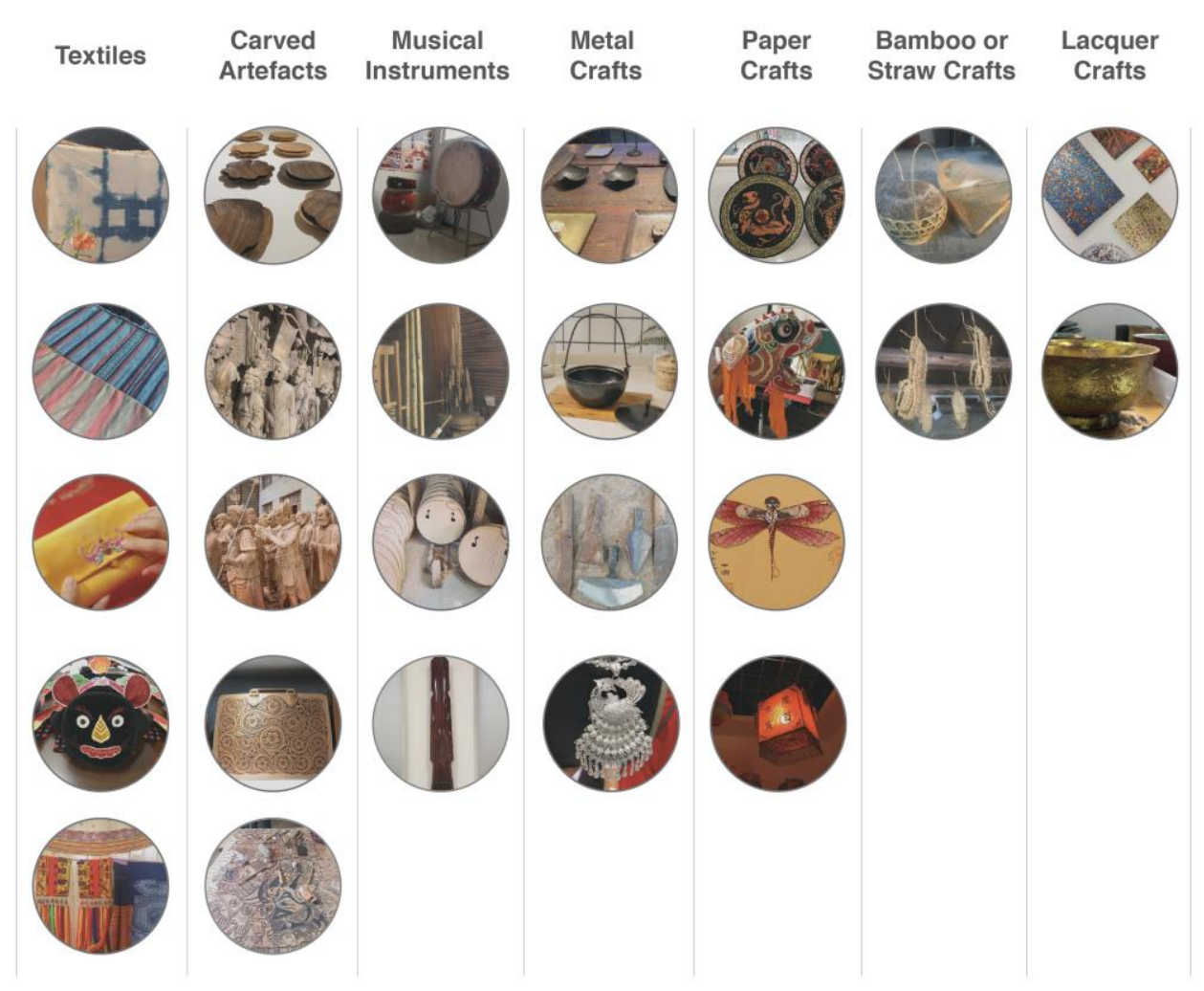

Figure 2. Overview of craft enterprises we visited (an earlier version of this diagram appeared in a paper by Zhang, 2021). 


\subsection{Data analysis}

From a constructive perspective, meaningful reality is constructed by human beings through interactions with the world, and developed and transmitted within an essentially social context (Crotty, 1998, p.42-43). In keeping with this methodology, our data analysis aims to reveal reality through constructed meanings and interpretations (Flick, 2004, p.89), and a series of place-based case studies of making practices in the Yellow River Valley region of central China are analysed in order to facilitate understandings of the:

- Social context in which each craft enterprise operates;

- Values and priorities of craft makers and enterprise owners;

- Relationship of maker enterprises to sustainability;

- Design opportunities.

\section{Findings}

The findings are presented around four key areas with associated visualisation tools: 1) relevance of place, 2) significant values, 3) relationship to sustainability, and 4) design opportunities.

\subsection{Relevance of place}

Here, eight context related factors were developed in order to examine the relevance of place and the services and opportunities available to small maker enterprises in a particular locale, which help support - or could help support - their business. These factors are described as follows:

- Resources: availability and access to local materials, availability of other materials, suppliers and service providers.

- Professional Development: availability of learning resources and training, in formats that are suited to small enterprise owners.

- Cultural Events: can provide opportunities for sales, dissemination, demonstrations, workshops, profile raising and increasing public awareness about heritage crafts and so on, e.g. festivals, fairs and dedicated markets, folk activities, ceremonies and rituals.

- Cultural Support Organisations: in the area-non-profit organisations, large companies and the media can often provide direct benefits to craft makers and their work, such as opportunities for exhibitions, the sale of goods, and an increased visibility and profile for craft practices and products.

- Policy: regional policies that helps sustain heritage making practices, such as those related to education and training, fund raising, taxation, and intellectual property.

- Infrastructure: appropriate infrastructure can indirectly support the viability of maker enterprises, such as transport links, an airport, hotels, restaurants.

- Attractions: these comprise a variety of elements such as tourist sites, regional cuisine, the natural beauty of the region, public galleries and museums - all these can significantly enhance the business opportunities of small maker enterprises.

- Profile: a region's national or international profile is a significant factor in attracting visitors and stimulating the local economy and the opportunities for small maker enterprises, such as gaining UNESCO World Heritage Site status.

We were informed by one local government official whom we interviewed that reviving traditional crafts is integrated into local long-term development programmes related to cultural heritage 
preservation and tourism economic development. According to our interviews with craft-makers and enterprise owners, regional policies help them raise their profile and sustain their craft skills. Such policies relate to education and training, fund raising, and designation of historic old craft brands. In response to the government's call, local institutions, media companies and relevant cultural organisations also directly benefit craftspeople and their craft business; for example, by offering opportunities for exhibitions and financial support.

Small craft enterprises producing products that are particularly associated with local provenance or that have regional cultural characteristics are being supported by top-down mechanisms. Also, our research reveals a strong relationship of small craft enterprises to place, especially in terms of the resources they use in the making and production. For example, our research into drum making in Luoyang city and inkstone carving in Zhengzhou city, show that locally available materials are given priority, including wood, leather and the clay-like mud from the banks of the Yellow River. However, the drum maker was forced to change from using local leathers to leather imported from the south of China because changes in local farming practices during the 1990s meant that local water buffalo were being killed for meat when they are still young. At this young age, the leather is not yet strong or thick enough for use as drum skins.

In addition, in-depth case studies on the drum-maker and inkstone carver provide a basis for demonstrating how the framework can be used to show how small craft enterprises can be developed. Referring to the diagrams below, we see that relevant business or training courses would be helpful for the drum maker to run his website and to do online promotion - Figure 3 shows the drum maker is currently not taking much advantage of the business opportunities offered by the Internet. In contrast, the inkstone carver, who has highly successful operation, is making good use of all the opportunities offered by 'place' as shown in Figure 4.

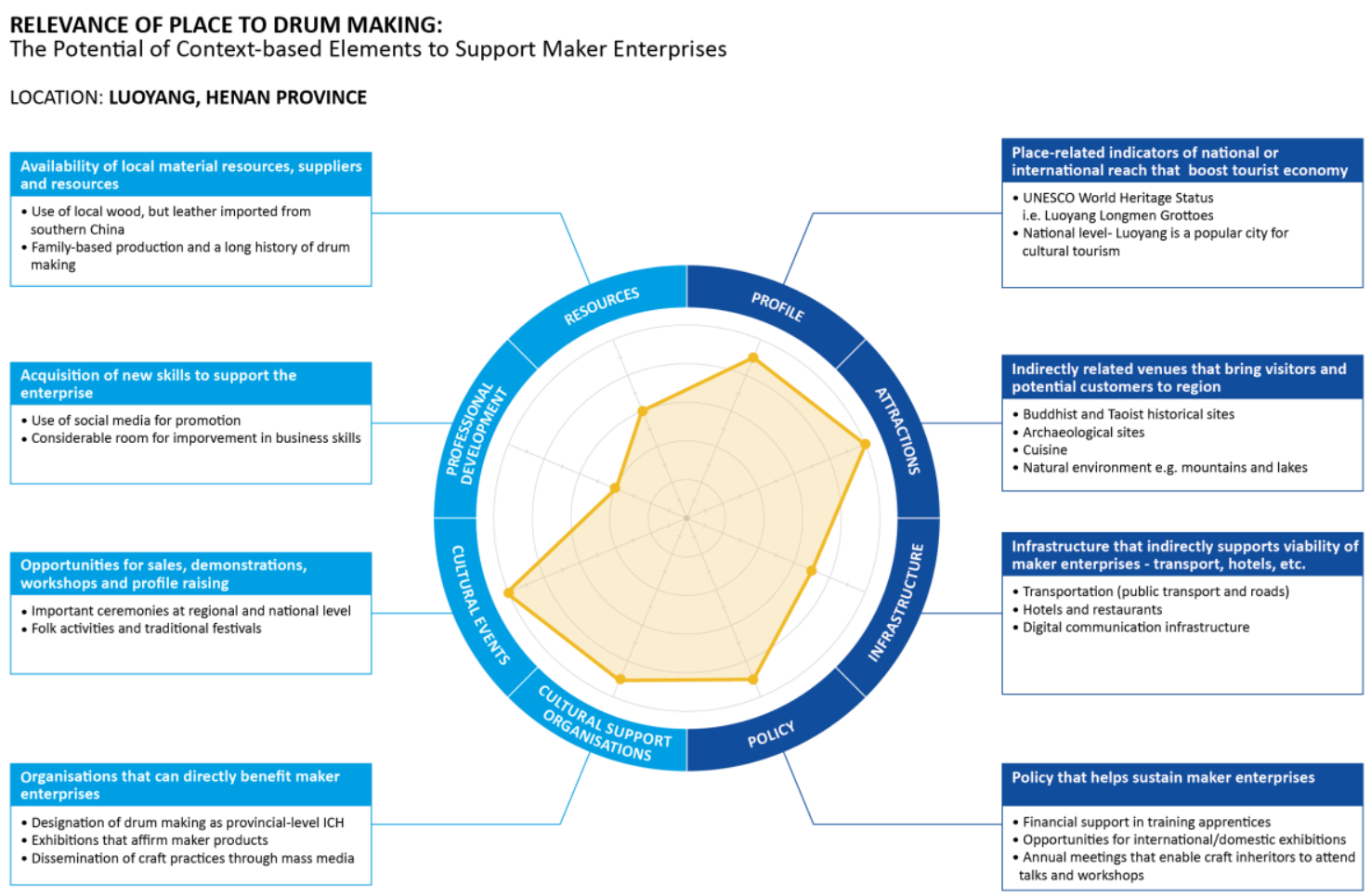


RELEVANCE OF PLACE TO INKSTONE CARVING:

The Potential of Context-based Elements to Support Maker Enterprises

LOCATION: ZHENGZHOU, HENAN PROVINCE

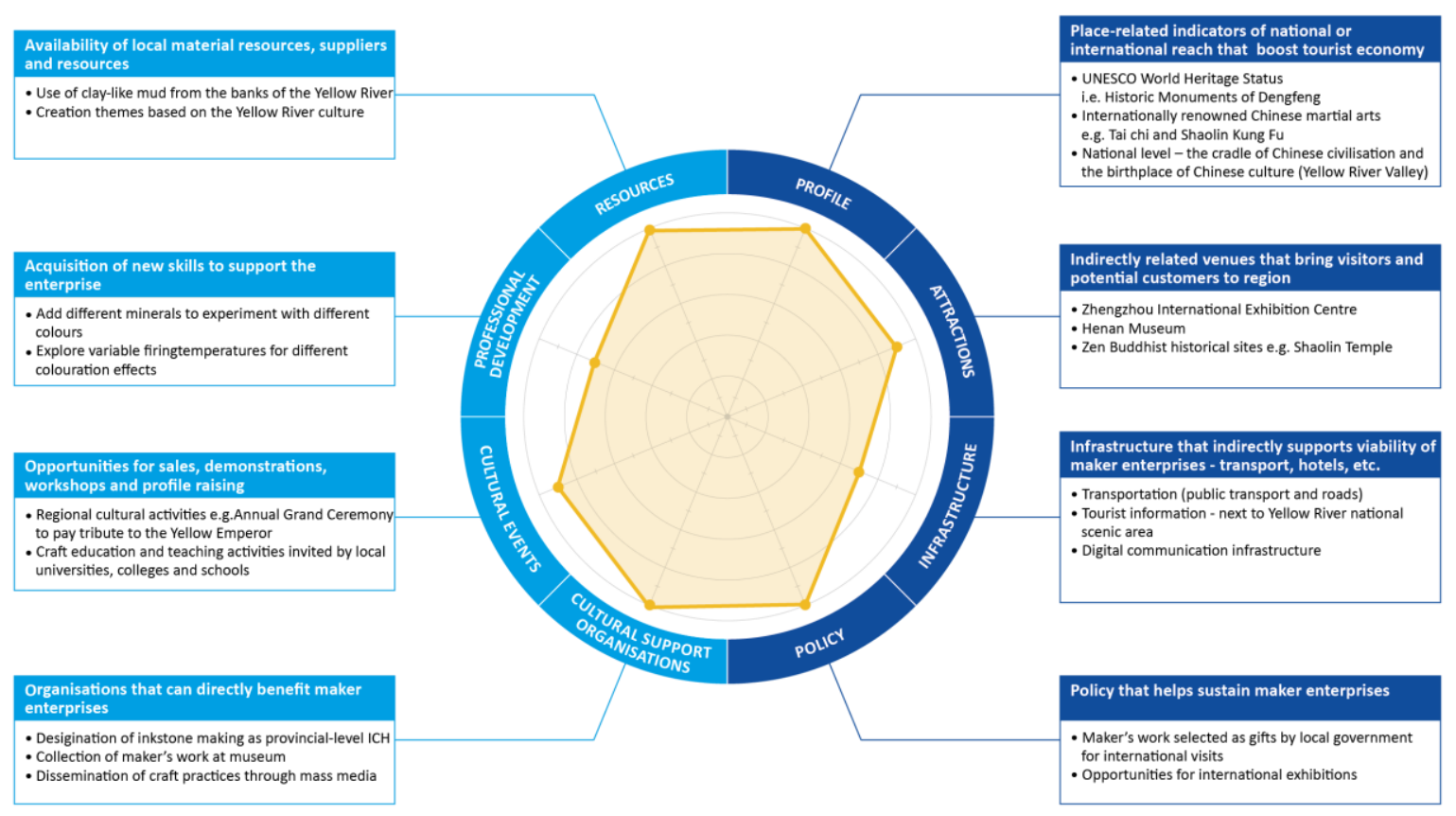

Note: the diagram is indicative rather than definitive

Figure 4. Relevance of place to inkstone carver's business.

\subsection{Significant values}

Craft making practices, particularly traditional ones, are vital to human culture as they are the expression of human values. The interviews and observations carried out with craft-makers and enterprise owners have been analysed through the lens of Schwartz's Values Circumplex (2012). Accordingly, the values that drive the nature of craft, can be understood under four categories, as described below:

- Innovation: Openness to the introduction of new techniques and technologies, and novelty and change (e.g. continuous development of new product types, patterns, product lines and designs).

- Conservation: Continuity and stability of working methods (i.e. a sense of responsibility to place, family- and/or community-based knowledge and skills, and a commitment to their conservation and continuation).

- Concern for Others - adherence to self-transcending or 'beyond-self' values: Welfare of people and planet (e.g. care for other people and nature beyond one's own immediate environment), and commitment to community (care for and contribution to those with whom one is in frequent contact, e.g. individual craft makers, neighbours).

- Self-Advancement - adherence to self-enhancing or 'self-oriented' values: Recognition by others (e.g. affirmation by peers and organisations through competitions, awards and prizes, selection for exhibitions, gallery representation), and personal ambition and prosperity (e.g. opportunities for individual development and income generation). 
Two specific craft examples were selected from the Yellow River Valley region to assist in understanding the different values and priorities of makers.

The first is a master leather craftsman who creates the prototypical designs, trains apprentices and run two leather products shops. His products are designed to suit the contemporary market and fashion trends and he focuses on the values of innovation, consumerism and self-expression. In contrast, the second, a traditional maker of large ceremonial lanterns (used in Chinese New Year festivals) feels a strong responsibility to spread knowledge and understanding of the traditions and to continuing the skills of traditional lantern making. He feels a sense of responsibility, especially as his family's lantern making business was included in the list of China's national ICH in 2008. To achieve these goals, he provides many free courses and arranges activities for students at primary, junior and high schools and universities each year. He has also converted his ancestral home to a lantern museum, which has free admission (see details in Figures 5 and 6).

It is obvious that these two makers are driven by very different values and priorities, which affect how they develop their craft businesses. In the lantern making, there is a stress on cultural transmission and heritage education, while the leather maker devotes himself to designing new leather products, responding to contemporary fashions and customer needs. A comparison between these two craft makers and their business is shown in Figure 7, which is a clear and powerful visual indication of their very contrasting values.

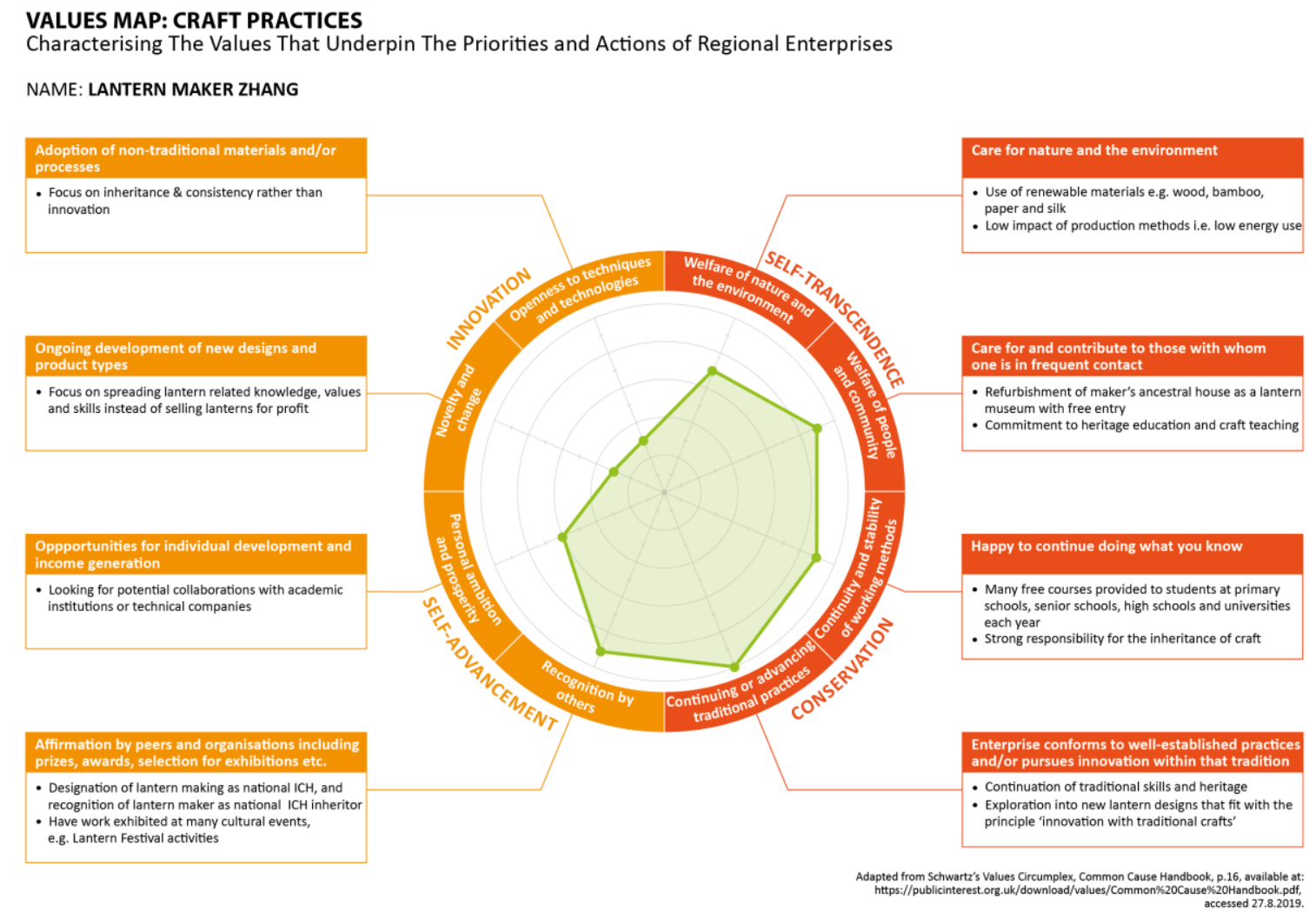

Figure 5. Value map - lantern maker Zhang's focus. 
Walker. S., Evans. M., \& Zhang. W.

VALUES MAP: CRAFT PRACTICES

Characterising The Values That Underpin The Priorities and Actions of Economic Development

NAME: LEATHER CARVER LI

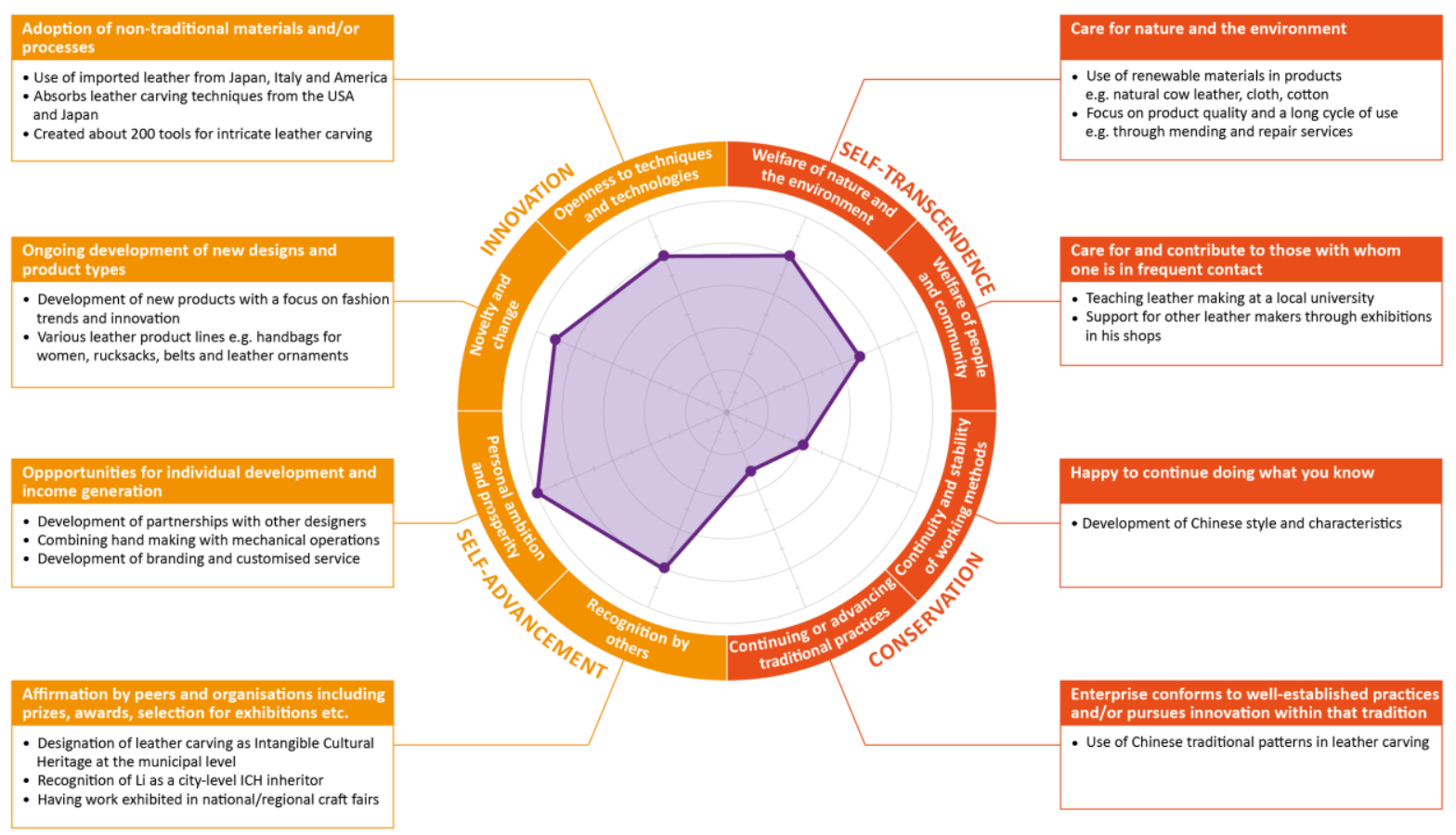

Figure 6. Value map - leather carver Li's enterprise.

COMPARISON OF VALUES: THE LANTERN MAKER AND THE LEATHERWARE MAKER

LOCATION: HENAN PROVINCE, CENTRAL CHINA

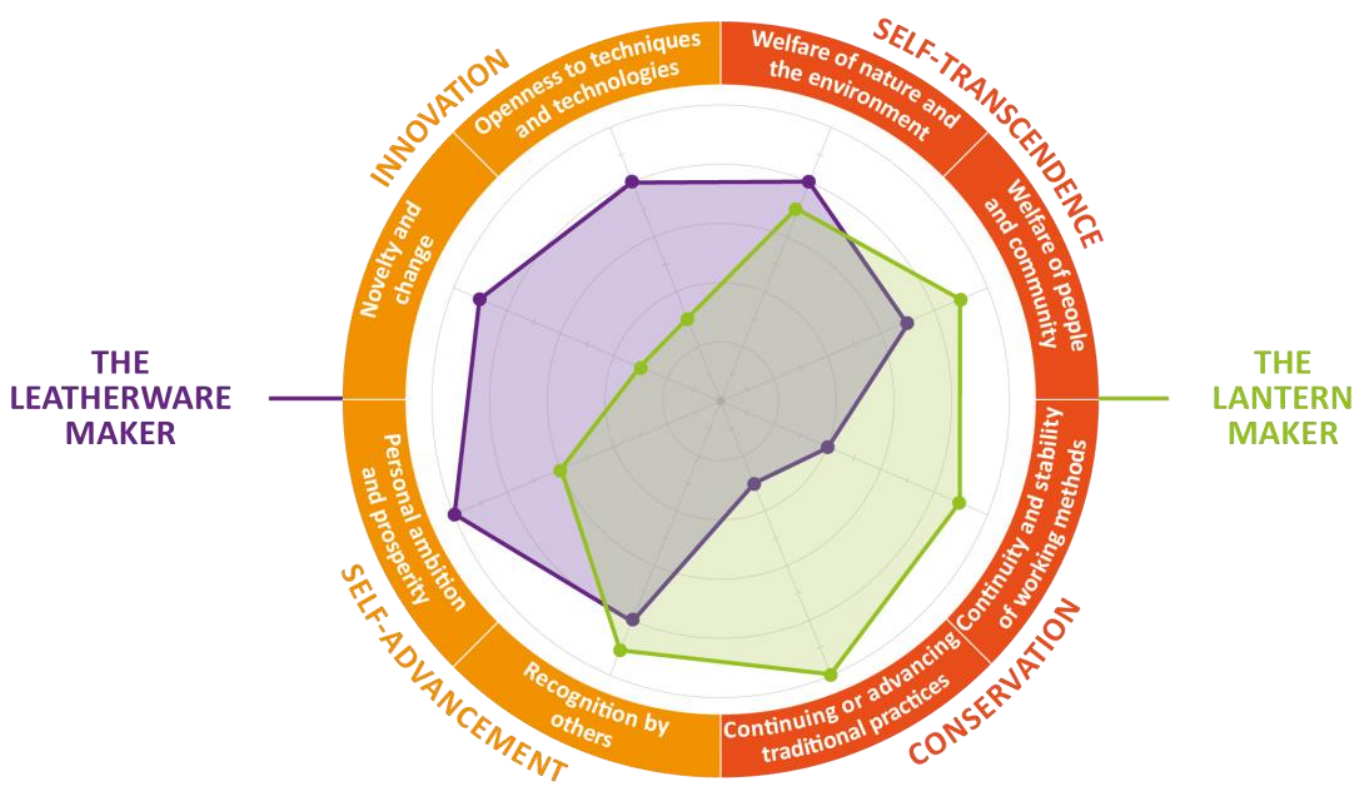

Figure 7. Comparison of values between the lantern maker and the leatherwear maker. 


\subsection{Relationship to Sustainability}

This research explores how design can contribute to the effective implementation of sustainable principles at the local level in small and micro maker enterprises. According to Walker's Quadruple Bottom Line of Design for Sustainability (Walker, 2011, p.187-190; 2014, p.92-93), the following four levels help to understand the relationship of the enterprise to sustainability:

- Practical meaning and environmental implications - utilitarian benefits plus the environmental repercussions of resource or materials acquisition, processes, making, packaging, marketing etc., including energy use and the production of waste.

- Social meaning - contribution to social equity, justice, community and culture.

- Personal meaning - ensuring enterprise activities are in accord with personal flourishing and non-selfish or 'beyond self' values.

- Economic means - ensuring economic viability of the enterprise in ways that accord with customer needs as well as one's own values, social responsibility, and environmental care.

From this, an indicative overall assessment of maker enterprises in the Yellow River Valley region of central China is attained by using a numerical equivalent for each the above ratings (Low $=1$; Med. = 2; High $=3$ ) and then estimating an overall 'indicative' rating based on the average of the four. Those individual areas currently assessed as 'Low' will be the ones to work on in the future if the overall assessment is to be improved (see details in Figure 8).

\section{SUSTAINABILITY PROFILE:}

Alignment of Maker Enterprise with Principles of Sustainability

NAME: YELLOW RIVER VALLEY REGION, CENTRAL CHINA

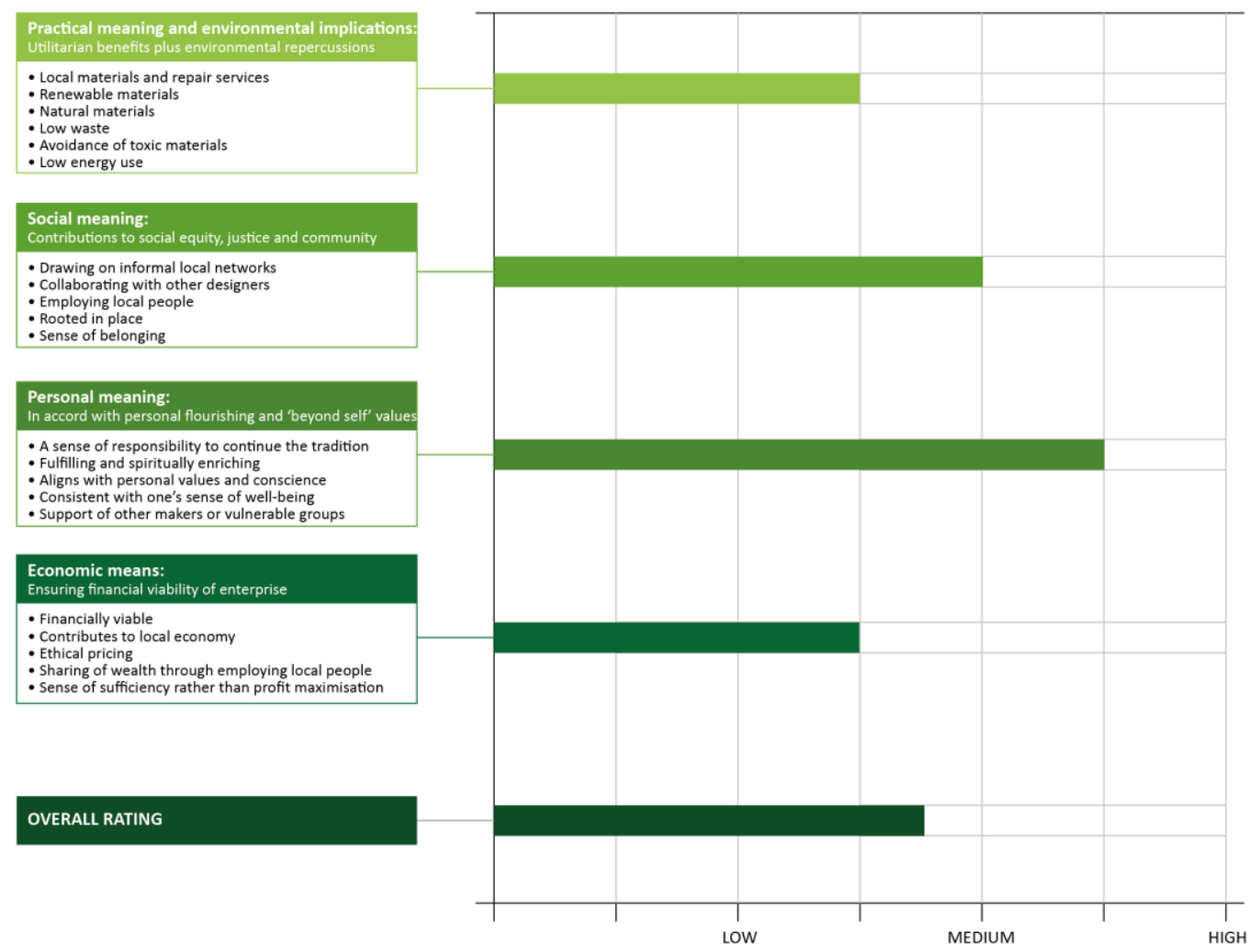

Figure 8. Sustainable profile of the Yellow River Valley region of central China. 


\subsection{Design Opportunities}

All enterprises and associated making practices are classified in a matrix under four categories, based on their product value/production cost profile, including lucrative products, everyday products, exclusive products and unviable products. Lucrative products have a high perceived value even though they may be made from relatively low-cost materials, employ low or moderate skills in their manufacture, or be relatively quick and easy to complete. Examples include textiles, leatherware, kitchenware and woodblock New Year prints of Yellow River Valley. For exclusive products, materials are relatively expensive, and the making is time-consuming and requires highlevel skills. Examples include musical instruments, jewellery, and large carved crafts, such as Buddhist sculptures or wall reliefs. Everyday products include bamboo basketry and straw sandals. These are made from low-cost materials using relatively low skills. Unviable products include paper oil umbrellas, paper lanterns and paper kites. These all employ high-level skills and are relatively difficult and time-consuming to make. Consequently, they have been largely replaced by massproduced alternatives. In addition, objects d'art such as decorative lacquer objects, are regarded as unviable products, because these are generally niche markets and are frequently not traditional. This last object category needs to be further explored.

Figure 9, shows these four categories of product types. In each of the quadrants, opportunities are identified as to where design might make a useful contribution for a particular product category. For example, in the case of Unviable Products, design could be used to:

- Develop new products that employ traditional skills, techniques and materials but reinvent the product to suit a contemporary market.

- Help increase the appreciation and perceived value of the product(s) through branding, packaging and storytelling in order to be able to command a more viable price point.

- Ensure production processes are efficient and effective, employ mechanical techniques where appropriate and ensure hand skills are used for the intricate finishing work only, thereby reducing production costs wherever possible.

- Catalogue and archive the practices, techniques and tools (including by video) so that if the craft does decline and disappear it could, potentially, be revived in the future. 
DESIGN OPPORTUNITIES:

Potential for Designers to Contribute to Maker Enterprises Based on Value/Cost Profile

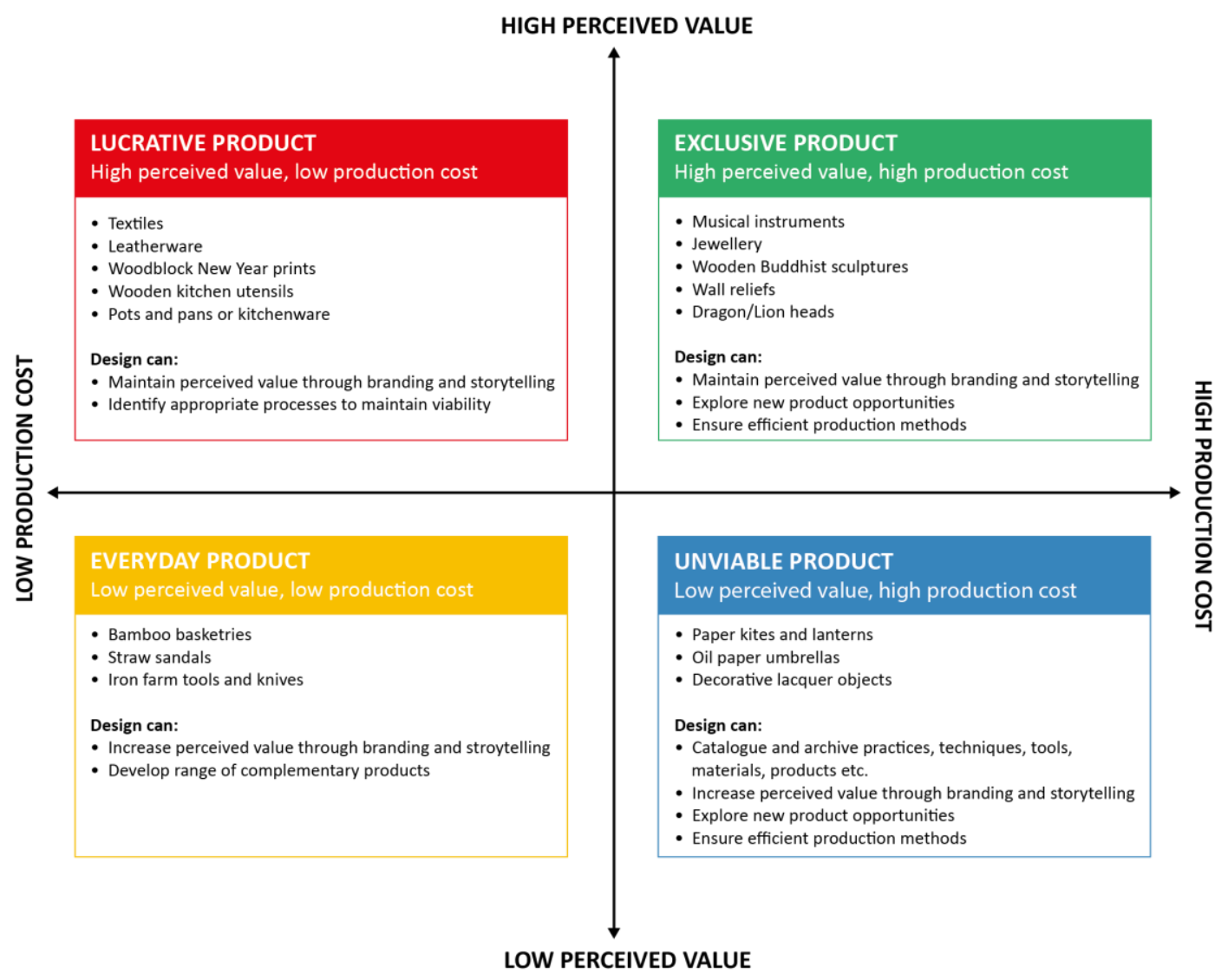

Figure 9. Potential for designers to contribute to maker enterprises in central China.

\section{Discussions and conclusions}

Through the analysis of primary data collected from the Yellow River Valley region of central China, this research has identified and visualised:

- the relationships of craft-makers and their businesses to 'localisation' and the significance of 'place' to their operation;

- the significance of intrinsic/extrinsic values and their relationship to the craft makers priorities and aspirations for the enterprise;

- the relationship of the enterprise to sustainability; and

- design opportunities in relation to production type and value.

Our in-depth studies of craft-makers and business in this region demonstrates that the Located Making Framework can be used as an effective method for understanding traditional making practices, their relevance to place, their underlying values, their relationship to sustainability and their future potential.

Four phrases are included in this framework. Firstly, context-related factors are considered to examine the relevance of place to the enterprises so as to make sense of what opportunities are offered by a particular locale that support - or could support - the business. Secondly, the values and priorities of craftmakers and enterprise owners were examined using a modified version of Schwartz's Values Circumplex (2012) to understand what drives the nature of their craft, the 
economic success of their business, and the relationship of their operations to sustainability. Thirdly, Walker's Quadruple Bottom Line of Design for Sustainability four categories are used to examine the sustainable performance of maker-enterprises, comprising practical meaning with environmental implications, social meaning, personal meaning, and economic means. Fourthly, by combining product value and cost profiles, the research identified where design might contribute effectively to improve the viability of the enterprise and to ensure the effective implementation of sustainability principles. Figure 10 conveys the analytical framework resulting from the research, and each phase of which has been explained in detail associated with case studies in the Findings.

This framework can be used by different people in different ways. By building a website that plots 'Value' data from many craft makers, individual makers can see how their values and motivations compare with others, and discuss this with them at meetings, conferences and other events organised by people involved in UNESCO ICH programme. Similarly, cumulative plots 'Connection to Place' allows individual makers to become better acquainted with the resources and facilities that a place can offer, such as suppliers, galleries, craft markets and other outlets. This facilitates knowledge exchange and mutual learning. In addition, the indicative 'Sustainability' plot can be used by individual makers and sector support organisations to improve practices so they better align with the four interrelated factors of the QBL. The 'Design Opportunities' diagram aligns the product(s) from a particular craft with opportunities for business development, which can help individuals and could be used by sector support organisations. Finally, policy makers can gain an idea of craft makers' priorities, values and motivations, and their ties to place in order to make informed, appropriate, and culturally sensitive policy recommendations and decisions.

\section{LOCATED MAKING FRAMEWORK}

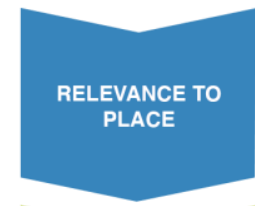

2

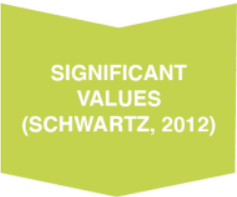

3

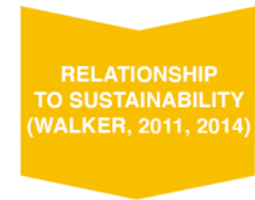

4

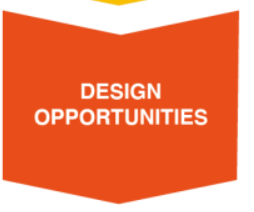

CONTEXT-RELATED FACTORS THAT SHOW THE RELEVANCE OF PLACE TO SMALL MAKER ENTERPRISES
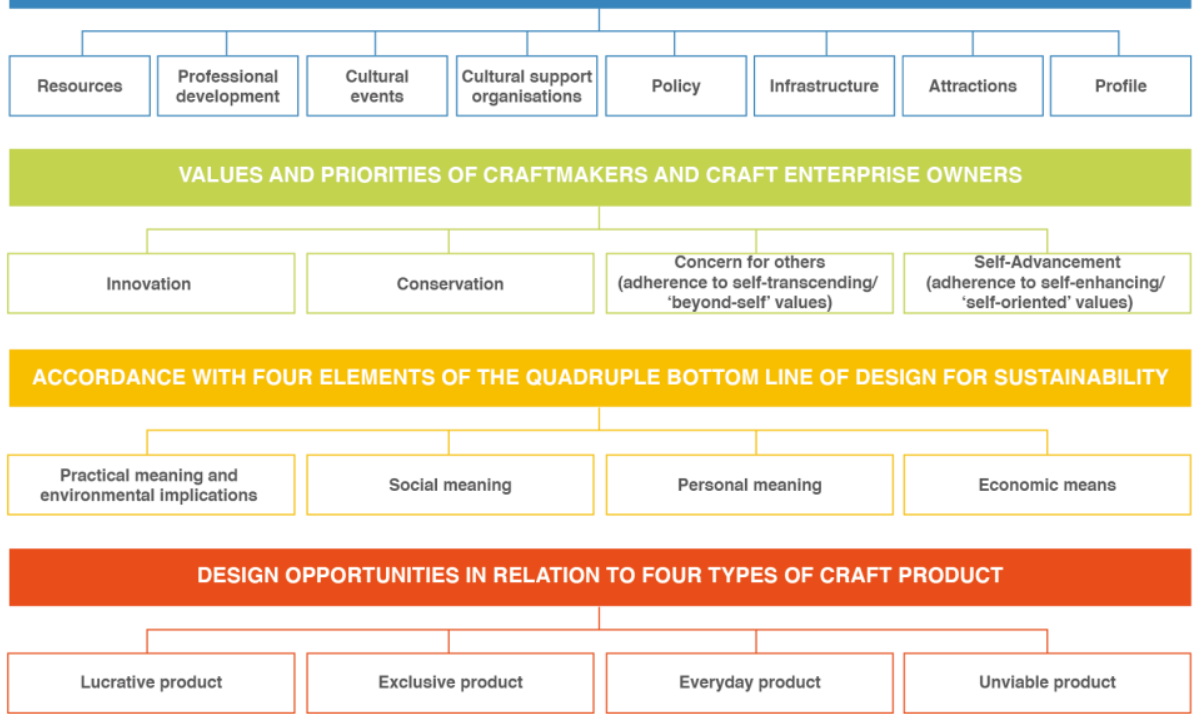

Figure 10. Located Making Framework.

Future plans for this work include developing an interactive online framework that will employ Likert-scale online questionnaires and automated plots. This will allow the framework to be used more widely, and enable makers to benefit from having access to key indicators derived from cumulative results. 


\section{References}

Bissett-Johnson, K., \& Moorhead, D. (2019). Co-creating craft; Australian designers meet artisans in India. Textile Society of America Symposium Proceedings. 1073. https://doi.org/10.32873/unl.dc.tsasp.0004

CGSS (Consulate General of Switzerland in Shanghai). (2012). The "Rise of Central China" Plan: Objectives and Impacts with Special Focus on Anhui Province. Retrieved May 15, 2021, from https://www.sinoptic.ch/shanghaiflash/texts/pdf/2012/201204_Shanghai.Flash.pdf

China Daily. (2017). Photography Captures China's Central Plain Culture. China Daily, April 13. https://www.chinadaily.com.cn/cul- ture/2017-04/13/content_28897052.htm.

Crotty, M. (1998). The Foundations of Social Research: Meaning and Perspective in the Research Process. London: Sage Publications.

ICH China. (n.d.). China's National List of the Representative Intangible Cultural Heritage. [in Chinese.] Retrieved May 3, 2021, from http://www.ihchina.cn/project.html

Flick, U. (2004). Constructivism. In Flick, U., Kardorff, E., and Steinke, I. (eds.) A Companion to Qualitative Research. pp.88-94. London: Sage Publications.

Kuah, K.E., \& Liu, Z. (2016). Intangible Cultural Heritage in Contemporary China and Hong Kong: An Introductory Overview. In Kuah, K.E., \& Liu, Z. (Eds.), Intangible Cultural Heritage in Contemporary China. pp.13-22. London: Routledge.

Luckman, S., \& Andrew, J. (2020). Craftspeople and Design Makers in the Contemporary Creative Economy. Cham: Palgrave Macmillan.

Murray, K. (2012). Outsourcing the hand: An Analysis of Craft-design Collaborations across the Global Divide. Craft + Design Enquiry, 2: 1-23. https://doi.org/10.22459/CDE.02.2010.04

Schwartz, S. H. (2012). An Overview of The Schwartz Theory of Basic Values. Online Readings in Psychology and Culture, 2 (1). https://doi.org/10.9707/2307-0919.1116

Temeltaş, H. (2017). Collaboration and Exchange between "Craftsman" and "Designer": Symbiosis towards Product Innovation. The Design Journal, 20(sup1), S3713-S3723. https://doi.org/10.1080/14606925.2017.1352876

Tung, F.W. (2012). Weaving with Rush: Exploring Craft-Design Collaborations in Revitalizing a Local Craft. International Journal of Design, 6 (3), 71-84. http://www.ijdesign.org/index.php/IJDesign/article/view/1077

UNESCO. (2003). Text of the Convention for the Safeguarding of the Intangible Cultural Heritage. Retrieved June 18, 2020, from https://ich.unesco.org/en/convention

Walker, S. (2011). The Spirit of Design: Objects, Environment and Meaning. London: Earthscan.

Walker, S. (2014). Designing Sustainability: Making Radical Changes in a Material World. London: Routledge.

Wang, P. (2019). Rise of Central China Strategy and the Economic Growth of Hubei Province. Modern Economy, 10(02): 502-512. https://doi.org/10.4236/me.2019.102034

Wang, S., Zhao, H., Chen, G., Xu, H., \& Demicoli, M. (2020). Anthracological Analysis from the Bronze Age Site of Erlitou (Henan province, China). Quaternary International. https://doi.org/10.1016/j.quaint.2020.10.002

Zhang, W. (2021). Design for the Sustainment of Traditional Making Practices: A Research Study in Central China. The Design Journal, 24(1), 137-147.

https://doi.org/10.1080/14606925.2020.1835232 
Author Bios:

Stuart Walker is Principal Investigator for the Located Making project; Chair of Design for Sustainability; and a Co-Director of ImaginationLancaster, which he co-founded at Lancaster University. He is also Visiting Professor, Kingston University and Professor Emeritus, University of Calgary.

Martyn Evans is Co-Investigator; Professor and Director of Manchester School of Art at MMU. He has led a number of major funded research projects, both in the United Kingdom and Europe and is a member of the AHRC's Advisory Board.

Wanlin Zhang is Researcher for this project and Ph.D. candidate at the ImaginationLancaster Design Research Centre, Lancaster University, under the supervision of Professor Stuart Walker. Her research interests include culturally significant designs and products, design for sustainability and craft-design collaborations.

Acknowledgements: We would like to acknowledge the Arts and Humanities Research Council (AHRC) and the Newton Fund for their funding support. We are also grateful for the contributions of our colleges at the Chinese Academy of Social Science, Beijing, China, and Ningxia University, China for their support during this research, as well as participant interviewees for their time. 